\title{
Isolation and characterization of a mutant of Neisseria gonorrhoeae that is defective in the uptake of iron from transferrin and haemoglobin and is avirulent in mouse subcutaneous chambers
}

\author{
Caroline A. Genco, ${ }^{*} \dagger$ Cheng-Yen Chen, Robert J. Arko, Darrell R. Kapczynski $\dagger$ and \\ STEPHEN A. MORSE
}

Division of Sexually Transmitted Diseases Laboratory Research, Center for Infectious Diseases, Centers for Disease Control, Atlanta, Georgia 30333, USA

(Received 10 August 1990; revised 7 December 1990; accepted 7 January 1991)

\begin{abstract}
Iron-uptake mutants of Neisseria gonorrhoeae strain $\mathbf{3 4 0}$ were obtained following treatment with streptonigrin, and one such mutant (Fud14) was characterized. $N$. gonorrhoeae strain Fud14 was unable to grow with human transferrin or haemoglobin as the sole source of iron, but grew normally with heat-inactivated normal human serum or haemin. Internalization of ${ }^{55} \mathrm{Fe}$ from transferrin by strain Fud14 was only $25 \%$ of the parent level. Strain Fud14 ( $\leq 1 \times 10^{8}$ c.f.u.) did not grow in subcutaneous chambers implanted in mice, whereas the parent strain was infective at an $\mathrm{ID}_{50}$ of $4.3 \times 10^{1}$ c.f.u. Supplementation of chambers with either normal human serum or haemin resulted in the establishment of strain Fud14 in vivo for at least $240 \mathrm{~h}$ post-inoculation. Electroporation of Fud14 with wild-type DNA and selection for growth on medium containing human transferrin resulted in a recombinant (Fud15) that was capable of utilizing haemoglobin, and was virulent in mice. These results suggest that a gonococcal strain defective in the ability to utilize in vivo iron sources is not capable of survival in vivo.
\end{abstract}

\section{Introduction}

The ability of a potential pathogen to acquire iron from its host is an important determinant of virulence and may determine the nature of the infection produced. In humans, the majority of the iron is found intracellularly as ferritin, haemosiderin or haem. Extracellular iron is bound primarily to the high affinity iron-binding glycoproteins, transferrin (TF) and lactoferrin (LF), which function to transport and maintain the iron in a soluble state (Bullen, 1981). Consequently, pathogenic bacteria possess mechanisms for utilizing the iron associated with these proteins. For many bacteria, iron acquisition is mediated by siderophores as well as by specialized outer-membrane proteins, some of which are involved in obtaining iron from the ferrisiderophore complexes (Neilands, 1981). Both siderophores and ironregulated proteins have been shown to be produced in

†Present address: Department of Oral Biology, Emory University School of Postgraduate Dentistry, Atlanta, Georgia 30322, USA.

Abbreviations: CDM, chemically defined medium; GCB medium, Gonococcal Base medium; LF, lactoferrin; TF, transferrin. vivo (Griffiths et al., 1983; Griffiths \& Humphreys, 1980; Sciortino \& Finkelstein, 1983).

Neisseria gonorrhoeae, like other pathogenic microorganisms, must obtain the iron necessary for its growth from its host. All clinical isolates of $N$. gonorrhoeae tested to date can grow with TF as the sole source of iron (Mickelsen \& Sparling, 1981); many can also utilize LF as the sole source of iron (Mickelsen et al., 1982; Schryvers \& Lee, 1989). N. gonorrhoeae and N. meningitidis can utilize free haemoglobin, haemoglobin bound to haptoglobin and free haem, but not haem bound to haemopexin or albumin (Dyer et al., 1987b).

$N$. gonorrhoeae, $N$. meningitidis and Haemophilus influenzae do not produce siderophores, yet all utilize TFbound iron. Iron acquisition from TF requires direct contact between the organisms and the iron-binding protein (Archibald \& DeVoe 1979, Simonson et al., 1982; McKenna et al., 1988, Schryvers, 1988) and involves iron-regulated outer-membrane proteins that appear to function as specific receptors (Ala'Aldeen et al., 1990; Griffiths et al., 1990; Lee \& Schryvers, 1988; Schryvers \& Morris, 1988a).

The aminoquinone agent streptonigrin causes DNA degradation (Cone et al., 1976) and has been used to 
isolate iron uptake $(f u d)$ mutants of Escherichia coli. The selective properties of streptonigrin are dependent upon a requirement for iron in order to exert a bactericidal effect (Yeowell \& White, 1982). Thus, bacteria containing low concentrations of intracellular iron are resistant to streptonigrin, whereas iron-replete organisms are killed. Dyer et al. (1987a) used streptonigrin to isolate fud mutants of $N$. meningitidis. Some of these mutants have been shown to be deficient in their ability to acquire iron from LF, TF and ferric citrate complexes. Tsai et al. (1988) examined a $\mathrm{TF}^{-}$mutant of $N$. meningitidis and found that it had decreased receptor activity. Scatchard analysis suggested that the TF receptor of this mutant had a normal affinity for TF but the copy number was reduced to $19 \%$ of the wild-type level. Dyer et al. (1988) have also described a pleiotropic fud mutant of $N$. meningitidis that was unable to utilize TF for growth and lacked a $70 \mathrm{kDa}$ iron-regulated protein. However, the 70$\mathrm{kDa}$ protein was probably not the TF receptor, since the mutant strain exhibited wild-type TF-binding activity (Tsai et al., 1988).

The availability of mutants of $N$. gonorrhoeae would help in the elucidation of the pathway of iron uptake as well as define the role of iron acquisition in gonococcal pathogenesis. We describe here the isolation and the in vitro and in vivo characterization of one such gonococcal fud mutant.

\section{Methods}

Bacteria and growth conditions. N. gonorrhoeae strain 340 (formerly V1) (Pro-/IB-6 transparent, non-piliated) was used in this study. This strain is highly antigenic and is capable of inducing immunity to a broad spectrum of heterologous strains in both mice and guinea pigs (Wong et al., 1979). Gonococci were routinely grown on Gonococcal Base (GCB) medium (Difco) containing $1 \%(\mathrm{v} / \mathrm{v})$ IsoVitaleX (BBL) at $37^{\circ} \mathrm{C}$ in a $5 \%(\mathrm{v} / \mathrm{v}) \mathrm{CO}_{2}$ atmosphere. To assess growth with a specific iron source, an iron-depleted, chemically defined medium (CDM) (Morse \& Bartenstein, 1980) was used. The phosphate concentration of the medium was lowered, and it was depleted of iron by treatment with Chelex-100 (Bio-Rad) as described by Dyer et al. (1987a). Solid medium was prepared by the addition of sterile molten purified agar (Difco) to a final concentration of $1.5 \%(\mathrm{w} / \mathrm{v})$.

To examine the kinetics of growth in liquid medium, gonococci were grown overnight on CDM agar, suspended in CDM broth, diluted into prewarmed CDM supplemented with the iron source of interest, and incubated at $37^{\circ} \mathrm{C}$ with vigorous aeration. Growth was monitored by measuring turbidity with a Klett-Summerson colorimeter at $540 \mathrm{~nm}$.

For plate assays, fresh overnight cultures of $N$. gonorrhoeae were diluted in molten $\left(48^{\circ} \mathrm{C}\right) \mathrm{CDM}$ agar medium containing $12.5 \mu \mathrm{M}$ Desferal (CIBA-Geigy) to a final cell density of $1 \times 10^{8}$ c.f.u. $\mathrm{ml}^{-1}$. Plates were poured immediately. After the medium solidified, $4 \mathrm{~mm}$ wells were cut in the plates and $50 \mu \mathrm{l}$ volumes of various iron sources were added to the wells. Plates were incubated at $37{ }^{\circ} \mathrm{C}$ in $5 \% \mathrm{CO}_{2}$ and were examined for growth surrounding the wells after 24 and $48 \mathrm{~h}$.

Iron sources. Iron sources used in this study included: $\mathrm{FeCl}_{3}$ and $\mathrm{Fe}\left(\mathrm{NO}_{3}\right)_{3}, 10 \mu \mathrm{M}$; haemin, 2 and $4 \mu \mathrm{M}$; iron-saturated $(5 \%$ or $30 \%)$ human TF and human LF, $5 \mu \mathrm{M}, 10 \mu \mathrm{M}$ and $30 \mu \mathrm{M}$; iron-saturated
$(30 \%)$ mouse $\mathrm{TF}, 5 \mu \mathrm{M}$; and $10 \%(\mathrm{v} / \mathrm{v})$ heat-inactivated normal human or mouse serum. Human TF, mouse TF, human LF, haemin, haemoglobin, $\mathrm{FeCl}_{3}$, and normal mouse serum were all obtained from Sigma. $\mathrm{Fe}\left(\mathrm{NO}_{3}\right)_{3}$ was purchased from Fisher Scientific. Normal human serum was obtained from the Centers for Disease Control (CDC) blood bank and heat-inactivated by heating at $56^{\circ} \mathrm{C}$ for $30 \mathrm{~min}$. TF and LF were saturated with iron as described by Simonson $e t$ al. (1982).

The haem content in uninoculated mouse chamber fluid and normal human serum dialysate was measured by obtaining a difference spectrum of the reduced versus oxidized pyridine haemochromogen and determining the $\Delta \boldsymbol{A}$ (Falk, 1964). Haemoglobin content was measured by first lysing uninoculated chamber fluid samples followed by the addition of $\mathrm{KCN}$ which resulted in the formation of a stable cyanmethaemoglobin complex. The concentration of haemoglobin was determined from the light absorption ratio of the cyanmethaemoglobin solution in a Micro cell counter (Sysmex, Japan).

Mutant isolation. Gonococci defective in the ability to utilize TFbound iron were isolated following treatment with streptonigrin (Sigma). Exponential phase gonococci were diluted into fresh GCB liquid medium and incubated at $37^{\circ} \mathrm{C}$ with vigorous aeration until the cells reached the late-exponential phase. Streptonigrin was added to the culture at a final concentration of $0.16 \mu \mathrm{g} \mathrm{ml}^{-1}$ and incubation continued for an additional $4.5 \mathrm{~h}$. Cells were harvested and washed by centrifugation, suspended in CDM, spread on GCB plates, and incubated for $24-48 \mathrm{~h}$. Colonies were transferred individually with toothpicks to $\mathrm{CDM}$ plates containing either $10 \mu \mathrm{M}-\mathrm{Fe}\left(\mathrm{NO}_{3}\right)_{3}$ or $5 \mu \mathrm{M}$ TF ( $30 \%$ iron-saturated) to identify colonies that were unable to grow with human TF as the sole source of iron.

Preparation of $\left[{ }^{55} \mathrm{Fe}\right] \mathrm{TF}$. Human apotransferrin (apoTF) was dissolved in $20 \mu \mathrm{M}$-sodium bicarbonate and $40 \mu \mathrm{M}$-Tris buffer (Trizma base, Sigma), pH 7·4, and dialysed against the same buffer for $6-8 \mathrm{~h}$. ${ }^{55} \mathrm{FeCl}_{3}$ (New England Nuclear) was complexed with a 10 -fold molar excess of sodium citrate and incubated with apoTF in Tris/bicarbonate buffer at room temperature for $30 \mathrm{~min}$, followed by dialysis against the same buffer overnight.

Iron Uptake. $\left[{ }^{55} \mathrm{Fe}\right] \mathrm{TF}(50 \%$ iron saturation and $2 \mu \mathrm{M}-\mathrm{TF})$ or $\left[{ }^{55} \mathrm{Fe}\right]$ ferric citrate $(2 \mu \mathrm{M})$ were used in iron uptake assays. All glassware was washed with $6 \mathrm{M}-\mathrm{HCl}$ and thoroughly rinsed in deionized water before use. Gonococci were grown in CDM to the exponential phase and cultures were diluted $1: 1$ into fresh CDM or CDM containing $10 \mu \mathrm{M}-\mathrm{KCN}$ and incubated for $10 \mathrm{~min}$ at $37^{\circ} \mathrm{C}$. A sample of cells $(250 \mu \mathrm{l})$ was added to an equal volume of medium that contained $\left[{ }^{55} \mathrm{Fe}\right] \mathrm{TF}$ or $\left[{ }^{55} \mathrm{Fe}\right] \mathrm{ferric}$ citrate and incubated for an additional $30 \mathrm{~min}$. Duplicate samples were diluted into $10 \mathrm{ml} 0 \cdot 1 \mathrm{M}$-sodium citrate (pH 7.4) containing $1 \mu \mathrm{M}-\mathrm{MgCl}_{2}$ and $0.25 \mathrm{~mm}-\mathrm{CaCl}_{2}$, and filtered through $0.45 \mu \mathrm{m}$ cellulose acetate filters. Filters were air-dried overnight, and the amount of cell-associated ${ }^{55} \mathrm{Fe}$ was determined by liquid scintillation spectrometry.

TF binding. TF binding to whole cells of $N$. gonorrhoeae 340 and Fud14 was determined by the method described by Tsai et al. (1988).

Fbp-associated iron. Gonococci were grown overnight on GCB agar and suspended in $50 \mathrm{ml}$ of CDM broth. The cultures were incubated at $37^{\circ} \mathrm{C}$ in a gyratory shaker. After reaching the mid-exponential phase of growth, the cells were used to inoculate $100 \mathrm{ml}$ of prewarmed CDM, and incubation was continued for another hour before the addition of $\left[{ }^{55} \mathrm{Fe}\right] \mathrm{TF}$ or $\left[{ }^{55} \mathrm{Fe}\right]$ ferric citrate. Cells were harvested after $2.5 \mathrm{~h}$ incubation with the labelled iron source, washed, and the Fbp was extracted and purified as described by Mietzner et al. (1987). Radioactivity associated with each fraction was determined by liquid scintillation spectrometry. 
Outer-membrane proteins. Gonococci grown to late exponential phase in iron-depleted $\mathrm{CDM}$ or $\mathrm{CDM}$ containing $10 \mu \mathrm{M}-\mathrm{Fe}\left(\mathrm{NO}_{3}\right)_{3}$ were used for the isolation of outer membranes. Outer membranes were prepared by extraction with sodium $N$-lauroylsarcosinate (Sarkosyl) at room temperature for $30 \mathrm{~min}$ (Mietzner et al., 1984). After centrifugation for $1 \mathrm{~h}(100000 \mathrm{~g})$, the outer-membrane pellet was suspended in water. Protein was determinined by the Lowry method with BSA as a standard. Outer-membrane preparations were then subjected to SDSPAGE using the discontinuous Laemmli buffer system (Laemmli, 1970). The protein-containing bands were visualized after staining with Coomassie blue and destaining in $10 \%(\mathrm{v} / \mathrm{v})$ acetic acid and $40 \%(\mathrm{v} / \mathrm{v})$ ethanol. Western blot analysis was done as described by Mietzner $e t$ al. (1986).

Experimental animals. Female mice from the Institute of Cancer Research (ICR), approximately 21-d-old, were used in these studies. Coil-shaped subcutaneous chambers were prepared from $0.5-\mathrm{mm}$ stainless steel wire and surgically implanted in the subcutaneous tissue of the dorsolumbar region of each mouse. At least $10 \mathrm{~d}$ elapsed before the chambers were inoculated. During this period, the outer incision healed completely, and the chambers became encapsulated by a thin layer of fibrous connective tissue containing small blood vessels. As the chambers became encapsulated within the subcutaneous tissue, they gradually filled with approximately $0.5 \mathrm{ml}$ of light-coloured transudate. Ten days after implantation, chambers were inoculated with $0.2 \mathrm{ml}$ of a suspension $\left(1 \times 10^{1}-1 \times 10^{8}\right.$ c.f.u. $)$ of $N$. gonorrhoeae 340 , Fud14 or Fud 15 in phosphate-buffered saline (PBS; $137 \mathrm{~mm}-\mathrm{NaCl}, 27 \mathrm{~mm}-\mathrm{KCl}$, $4.3 \mathrm{~mm}-\mathrm{Na}_{2} \mathrm{HPO}_{4}, 1.4 \mathrm{~mm}-\mathrm{KH}_{2} \mathrm{PO}_{4}, \mathrm{pH} 7 \cdot 2$ ). Chamber fluid was removed from each implanted chamber with a hypodermic needle and syringe at $1,2,5,15$ and $30 \mathrm{~d}$ post-inoculation for bacteriological culture and microscopic examination. ID $_{50}$ valves were determined $24 \mathrm{~h}$ post-inoculation.

Growth of $N$. gonorrhoeae strains 340 and Fud14 in chambers supplemented with either haemin or $10 \%$ normal human serum was also determined. Chambers were inoculated with $0.2 \mathrm{ml}$ of a suspension $\left(1 \times 10^{8}\right.$ c.f.u. $)$ of $N$. gonorrhoeae 340 or Fud14 in PBS alone, PBS containing $10 \%$ heat-inactivated normal human serum, or PBS containing $2 \mu \mathrm{M}$-hemin. Chamber fluid was removed at $4,24,48,72$, 144 and $240 \mathrm{~h}$ post-inoculation and examined as above.

All animals were maintained in animal care facilities fully accredited by the American Association for Accreditation of Laboratory Animal Care.

Electroporation. This was performed using a Gene Pulser apparatus (Bio-Rad). Chromosomal DNA was isolated from N. gonorrhoeae 340 by the method of Marmur (1961). Gonococci were scraped from overnight growth on GCB agar and washed in $1 \mathrm{ml}$ of electroporation buffer (EB: $272 \mathrm{~mm}$-sucrose, $1 \mathrm{~mm}-\mathrm{MgCl}_{2}, \mathrm{pH} \mathrm{7.4,15 \%}$, v/v glycerol). Cells were centrifuged $(11500 \mathrm{~g})$ and resuspended in $1 \mathrm{ml}$ of EB. After three washings, $50 \mu \mathrm{l}$ of cell suspension was mixed with an equal volume of strain 340 chromosomal DNA to a final concentration of $0.05 \mu \mathrm{g} \mathrm{DNA} \mu l^{-1}$ and pipetted into a cold $0.2 \mathrm{~cm}$ cuvette. Cells were pulsed $\left(2.5 \mathrm{kV} \mathrm{cm}^{-1}, 25 \mu \mathrm{F}, 800 \Omega\right)$ and $1 \mathrm{ml}$ of prewarmed GCB was immediately added to the cuvette. The pulsed gonococci were transferred to a $50 \mathrm{ml}$ flask containing $4 \mathrm{ml}$ of prewarmed GCB and incubated in a shaking water-bath at $37^{\circ} \mathrm{C}$ for $4.5 \mathrm{~h}$. At the end of this expression period, cells were plated onto CDM agar containing $10 \mu \mathrm{M}-$ $\mathrm{TF}(30 \%$ iron-saturated) to identify-colonies that were able to utilize TF as an iron source.

\section{Results}

\section{Characterization of growth in vitro}

The use of streptonigrin to enrich for fud mutants of $N$. gonorrhoeae strain 340 resulted in the isolation of several
Table 1. Growth of N. gonorrhoeae 340, Fud 14 and Fud15 in chemically defined medium supplemented with various iron sources

Growth was assessed by a plate assay and confirmed in liquid medium. ++ , Good growth; + , moderate growth; - , no growth; NT, not tested. Results are from one experiment and are representative of three separate experiments.

\begin{tabular}{lccc}
\hline \hline & \multicolumn{3}{c}{ Strain } \\
\cline { 2 - 4 } Iron source* & 340 & Fud14 & Fud15 \\
\hline Human TF & ++ & - & ++ \\
Mouse TF & - & - & $\mathrm{NT}$ \\
Human LF & - & - & - \\
Human serum & ++ & ++ & ++ \\
Mouse serum & - & - & $\mathrm{NT}$ \\
Haemin & ++ & + & + \\
Haemoglobin & ++ & - & ++ \\
Ferric citrate & ++ & + & ++ \\
\hline \hline
\end{tabular}

* The concentrations of iron sources and percentage saturation with iron of the TFs and LF are given in Methods.

mutants that were unable to grow on CDM agar containing $5 \mu \mathrm{M}$-TF ( $30 \%$ iron-saturated) as the sole source of iron. One such mutant, designated Fud14, was characterized extensively and is described here. The auxotype (Pro ${ }^{-}$) and serovar (IB-6) of Fudl4 were identical to those of the parent strain. Like the parent strain, Fud14 was non-piliated when grown on typing medium; piliated colony types were not observed with either strain 340 or Fud14.

The growth of strains 340 and Fud14 in CDM supplemented with various iron sources was compared (Table 1). $N$. gonorrhoeae Fud14 did not grow in CDM supplemented with either TF or haemoglobin; growth was observed in medium supplemented with either $10 \%$ heat-inactivated normal human serum or haemin $(4 \mu \mathrm{M})$. When normal human serum was dialysed, it could no longer support the growth of Fudl4 (data not shown). Strains 340 and Fud14 did not grow on medium supplemented with either human LF, mouse TF $(30 \%$ iron-saturated) or heat-inactivated normal mouse serum $(10 \% \mathrm{v} / \mathrm{v})$.

The growth kinetics of strain Fud14 in liquid CDM supplemented with either $\mathrm{Fe}\left(\mathrm{NO}_{3}\right)_{3}$ or heat-inactivated normal human serum were similar to those of strain 340 (data not shown). When human TF was substituted for the human serum, a marked difference was observed in both the growth rate and the final cell density of strain Fud14 (Fig. 1). N. gonorrhoeae strain Fud14 exhibited a generation time of $180 \mathrm{~min}$ in comparison with the parent strain, which had a generation time of $80 \mathrm{~min}$. Characteristically, cultures of strain Fud14 underwent only one doubling before reaching the stationary phase. 
Table 2. ${ }^{55} \mathrm{Fe}$ uptake by $N$. gonorrhoeae strains 340 and Fud14

The results are expressed as the mean $\pm \mathrm{SD}$ of three separate experiments.

\begin{tabular}{|c|c|c|c|c|c|c|}
\hline \multirow[b]{3}{*}{ Strain } & \multicolumn{4}{|c|}{$\begin{array}{c}\text { Cell-associated }{ }^{55} \mathrm{Fe} \\
\text { [pmol (mg protein })^{-1} \text { after } 30 \mathrm{~min} \text { incubation] }\end{array}$} & \multirow{2}{*}{\multicolumn{2}{|c|}{$\begin{array}{l}{ }^{55} \mathrm{Fe} \text { uptake } \\
{\left[\mathrm{pmol}(\mathrm{mg} \text { protein })^{-1}\right.} \\
\text { after } 30 \mathrm{~min} \\
\text { incubation*] }\end{array}$}} \\
\hline & \multicolumn{2}{|c|}{$\left[{ }^{55} \mathrm{Fe}\right]$ Ferric citrate $\dagger$} & \multicolumn{2}{|c|}{$\left[{ }^{55} \mathrm{Fe}\right] \mathrm{TF} \ddagger$} & & \\
\hline & Untreated & $\begin{array}{l}\mathrm{KCN}- \\
\text { treated }\end{array}$ & Untreated & $\begin{array}{l}\mathrm{KCN}- \\
\text { treated }\end{array}$ & $\begin{array}{l}\text { Ferric } \\
\text { citrate }\end{array}$ & $\begin{array}{l}\text { TF-bound } \\
\text { iron }\end{array}$ \\
\hline 340 & $1088( \pm 69)$ & $16( \pm 2)$ & $707 \cdot 4( \pm 24)$ & $7.4( \pm 0.4)$ & 1072 & 700 \\
\hline Fud 14 & $445 \cdot 5( \pm 9)$ & $3 \cdot 5( \pm 0 \cdot 3)$ & $179 \cdot 6( \pm 29)$ & $4.6( \pm 0.4)$ & 442 & 175 \\
\hline
\end{tabular}

* Iron uptake was calculated as the difference between the ${ }^{55} \mathrm{Fe}$ associated with untreated versus $\mathrm{KCN}$. treated cells.

$\dagger$ Concentration, $2 \mu \mathrm{M}$.

$\ddagger$ Concentration of $30 \%$ iron-saturated TF, $6 \cdot 25 \mu \mathrm{M}$.

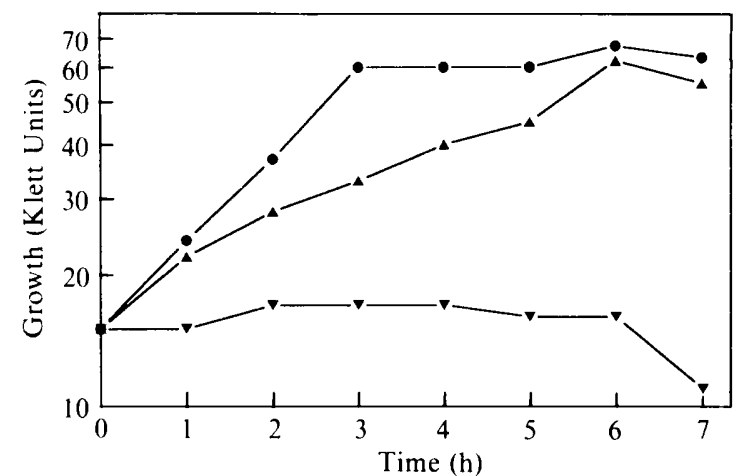

Fig. 1. Growth kinetics of $N$. gonorrhoeae in the presence of human TF. Gonococci were grown overnight in CDM agar, suspended in CDM broth and diluted in CDM supplemented with $5 \mu \mathrm{M}$-transferrin $(30 \%$ iron-saturated); and growth was monitored by measuring the optical density as described in Methods. $\odot$, strain $340 ; \nabla$, strain Fud14; $\mathbf{\Delta}$, strain Fud15. Results are from one experiment and are representative of four separate experiments.

Growth of strain Fud14 in complex medium containing excess iron (GCB) was identical to that of strain 340 with respect to the generation time and final cell yield (data not shown). The growth of Fud14 was inhibited to the same extent as that of the parent strain in complex medium (GCB) made iron-limiting by the addition of either 12.5 or $25 \mu \mathrm{M}$-Desferal (data not shown).

\section{Iron uptake}

The uptake of iron from $\left[{ }^{55} \mathrm{Fe}\right]$ ferric citrate and $\left[{ }^{55} \mathrm{Fe}\right] \mathrm{TF}$ by strains 340 and Fud 14 is shown in Table 2 . The ${ }^{55} \mathrm{Fe}$ associated with $\mathrm{KCN}$-treated cells represents material bound to the surface of the gonococcus, but not internalized. The amount of $\left[{ }^{55} \mathrm{Fe}\right] \mathrm{ferric}$ citrate that was associated with the KCN-treated cells of strain 340 and
Fud 14 was $1.5 \%$ and $0.8 \%$, respectively, of the amount associated with the untreated cells. In contrast, the amount of $\left[{ }^{55} \mathrm{Fe}\right] \mathrm{TF}$ associated with the $\mathrm{KCN}$-treated cells of strain 340 and Fudl4 was $10.5 \%$ and $2.6 \%$, respectively, of the amount associated with the untreated cells. The higher amount of cell-associated $\left[{ }^{55} \mathrm{Fe}\right] \mathrm{TF}$ probably reflects TF bound to its outer-membrane receptor (Ala'Aldeen et al., 1990; Griffiths et al., 1990; Lee \& Schryvers, 1988). The amount of iron internalized by strain Fud 14 from $\left[{ }^{55} \mathrm{Fe}\right]$ ferric citrate and $\left[{ }^{55} \mathrm{Fe}\right] \mathrm{TF}$, expressed as the difference between the ${ }^{55} \mathrm{Fe}$ associated with the untreated and $\mathrm{KCN}$-treated cells, was significantly lower than that internalized by the parent strain. Strain Fud 14 internalized $59 \%$ less iron from $\left[{ }^{55} \mathrm{Fe}\right]$ ferric citrate and $75 \%$ less iron from $\left[{ }^{55} \mathrm{Fe}\right] \mathrm{TF}$ than strain 340. The latter may be due to a defect in TF binding by Fud14. However, binding studies utilizing TF conjugated to horseradish peroxidase indicated that the parent and mutant strains bound TF to the same extent (data not shown). It was notable that the difference in the amount of iron internalized from $\left[{ }^{55} \mathrm{Fe}\right]$ ferric citrate was only $13 \%$ less in the mutant than with the parent strain when measured over a period of $150 \mathrm{~min}$ (Table 3), suggesting that the kinetics of uptake may be different.

\section{Association of iron with Fbp}

Preliminary experiments determined that some ${ }^{55} \mathrm{Fe}$ was associated with the $37 \mathrm{kDa}$ iron-regulated protein, $\mathrm{Fbp}$, after incubation of gonococci with [ $\left.{ }^{55} \mathrm{Fe}\right] \mathrm{TF}$. In order to ascertain whether Fud14 was capable of removing the iron from TF, we determined the iron from $\left[{ }^{55} \mathrm{Fe}\right] \mathrm{TF}$ and $\left[{ }^{55} \mathrm{Fe}\right]$ ferric citrate that was bound to the $\mathrm{Fbp}$ of strains Fud 14 and 340 after the isolation and purification of this protein from cells incubated in CDM containing the labelled iron source. The results (Table 3) indicate that 
Table 3. Assocation of iron from $\left[{ }^{55} \mathrm{Fe}\right] \mathrm{TF}$ and $\left[{ }^{55} \mathrm{Fe}\right]$ ferric citrate with whole cells and the Fbp of $N$. gonorrhoeae strains 340 and Fud 14

Cells were incubated for $2 \mathrm{~h}$ in CDM containing $6.25 \mu \mathrm{M}-\left[{ }^{55} \mathrm{Fe}\right] \mathrm{TF}(50 \%$ iron-saturated $)$ or for $2.5 \mathrm{~h}$ in CDM containing $2 \mu \mathrm{M}-\left[{ }^{55} \mathrm{Fe}\right]$ ferric citrate. Results are expressed as pmol ${ }^{55} \mathrm{Fe}$ (mg total protein) $)^{-1}$.

\begin{tabular}{|c|c|c|c|c|c|c|}
\hline \multirow[b]{3}{*}{ Strain } & \multicolumn{3}{|c|}{$\left[{ }^{55} \mathrm{Fe}\right] \mathrm{TF}$} & \multicolumn{3}{|c|}{$\left[{ }^{55} \mathrm{Fe}\right]$ Ferric citrate } \\
\hline & \multirow{2}{*}{$\begin{array}{c}\text { Cell- } \\
\text { associated } \\
{ }^{55} \mathrm{Fe}\end{array}$} & \multicolumn{2}{|c|}{ Fbp-bound ${ }^{55} \mathrm{Fe}$} & \multirow{2}{*}{$\begin{array}{c}\text { Cell- } \\
\text { associated } \\
{ }_{s s} \mathrm{Fe}\end{array}$} & \multicolumn{2}{|c|}{ Fbp-bound ${ }^{55} \mathrm{Fe}$} \\
\hline & & Total & $\% *$ & & Total & $\% *$ \\
\hline 340 & 4568 & 26 & $28 \cdot 5$ & 2900 & 29 & $50 \cdot 0$ \\
\hline Fud 14 & 831 & 17 & $102 \cdot 3$ & 2520 & 9 & 17.9 \\
\hline
\end{tabular}

* Calculation based on the estimate that Fbp comprises $2 \%$ of the total cellular protein.

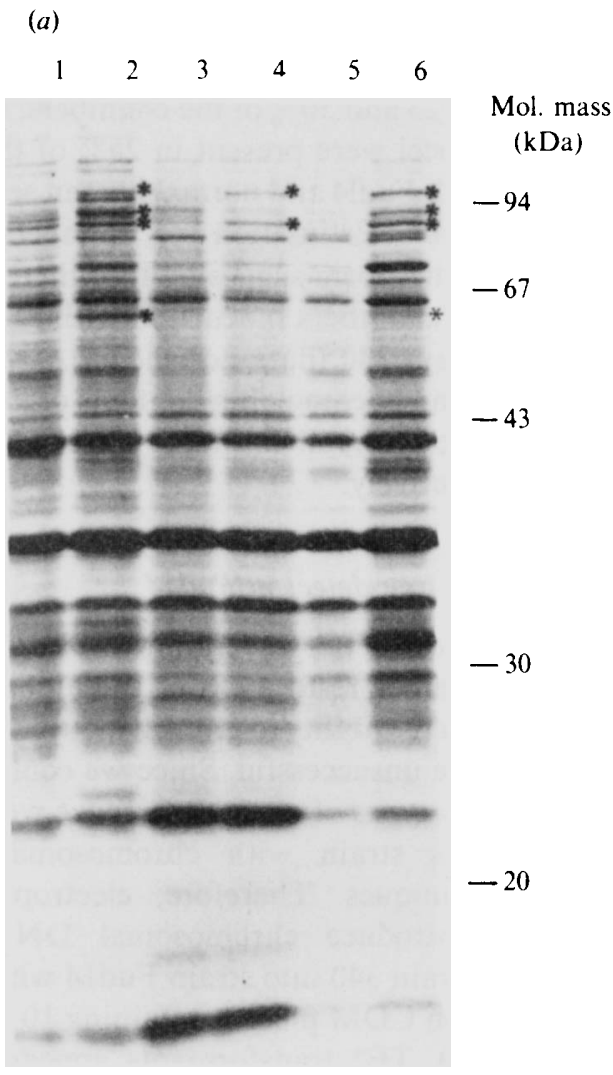

(b)

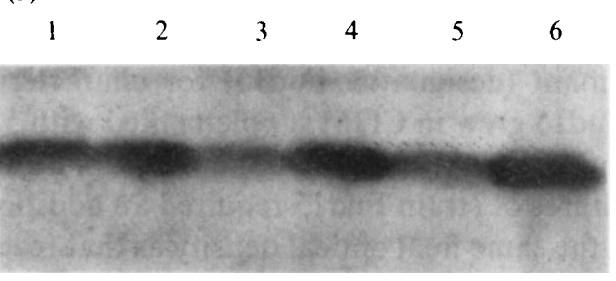

Fig. 2. SDS-PAGE of Sarkosyl-insoluble outer-membrane preparations. (a) Coomassie-blue-stained gel. $N$. gonorrhoeae strains 340 (lanes 1 and 2), Fud 14 (lanes 3 and 4 ) and Fud 15 (lanes 5 and 6) were grown in either $\mathrm{CDM}+10 \mu \mathrm{M}-\mathrm{Fe}\left(\mathrm{NO}_{3}\right)_{3}$ (lanes 1, 3 and 5) or deferrated $\mathrm{CDM}$ while strain Fud 14 had $82 \%$ less cell-associated iron than strain 340 after $2 \mathrm{~h}$ of incubation in CDM containing $\left[{ }^{55} \mathrm{Fe}\right] \mathrm{TF}$, the Fbp isolated from strain Fud14 had only $35 \%$ less iron than the Fbp isolated from strain 340 . Western blots of purified Fbp probed with anti-TF indicated that TF did not co-purify with the Fbp (data not shown). Both strains Fud 14 and 340 contained similar amounts of cell-associated iron after incubation for $2.5 \mathrm{~h}$ in $\mathrm{CDM}$ containing $\left[{ }^{55} \mathrm{Fe}\right] \mathrm{ferric}$ citrate. However, the amount of iron associated with the Fbp of strain Fud 14 was $68 \%$ less than that associated with the Fbp from strain 340 .

\section{Outer-membrane composition}

Outer membranes were prepared by Sarkosyl extraction from strains 340 and Fud 14 grown under iron-excess and iron-limited conditions and compared by SDS-PAGE. An examination of the outer-membrane protein profile revealed differences in the iron-regulated proteins (Fig. $2 a$ ). N. gonorrhoeae strain 340 expressed iron-regulated proteins with apparent molecular masses of 103, 93, 89 and $57 \mathrm{kDa}$. Strain Fud 14 expressed the 103 and $89 \mathrm{kDa}$ iron-regulated proteins at levels similar to that observed with strain 340; however, Fud14 did not produce detectable levels of the $57 \mathrm{kDa}$ iron-regulated protein. The $93 \mathrm{kDa}$ protein did not appear to be produced in Fud 14 under iron-limited conditions. In addition, Fud 14 did not produce a protein of apparent molecular mass $100 \mathrm{kDa}$, which was produced by strain 340 under both iron-limited and iron-excess conditions. Both strains

(lanes 2, 4 and 6). Iron-regulated outer-membrane proteins are marked with an asterisk $\left({ }^{*}\right)$. Molecular mass standards are shown on the right. (b) Autoradiograph of a Western blot probed with rabbit antiserum specific for the gonococcal Fbp and detected with ${ }^{125}$ I-labelled protein A. N. gonorrhoeae strains 340 (lanes 1 and 2), Fud 14 (lanes 3 and 4) and Fud 15 (lanes 5 and 6) were grown in either $\mathrm{CDM}+10 \mu \mathrm{M}-\mathrm{Fe}\left(\mathrm{NO}_{3}\right)_{3}$ (lanes 1, 3 and 5) or deferrated CDM (lanes 2, 4 and 6). 
Table 4. Recovery of $N$. gonorrhoeae from subcutaneous chambers supplemented with normal human serum $(N H S)$ or haemin

There were four mice in each group. Values represent the percentage of chambers with viable gonococci. NT, Not tested.

\begin{tabular}{rccccccr}
\hline \hline \multirow{2}{*}{$\begin{array}{c}\text { Time } \\
\text { (h) }\end{array}$} & Strain 340 & & & \multicolumn{3}{c}{ Strain Fud14 } \\
\cline { 2 - 4 } \cline { 6 - 8 } & Control & NHS & Haemin & & Control & NHS & Haemin \\
\hline 4 & 100 & 100 & 100 & & 100 & 100 & 100 \\
24 & NT & NT & NT & 50 & 50 & 50 \\
48 & NT & NT & NT & 25 & 50 & 25 \\
72 & 100 & 100 & 100 & & 0 & 50 & 25 \\
144 & 100 & 100 & 100 & & 0 & 50 & 25 \\
240 & 100 & NT & NT & 0 & 25 & 0 \\
\hline \hline
\end{tabular}

produced the Fbp as demonstrated by probing Western blots with affinity purified rabbit polyclonal anti-Fbp serum (Fig. 2b). Typically, low levels of Fbp were synthesized by gonococci grown in $\mathrm{CDM}+\mathrm{Fe}\left(\mathrm{NO}_{3}\right)_{3}$. This is most likely due to the EDTA in CDM which may create some degree of iron restriction in itself. Fbp comigrates with the protein I of strains 340 and Fud14 under the gel conditions used in this study.

Strains 340 and Fud14 grew as transparent colony variants on gonococcal typing medium. However, both strains produced a similar heat-modifiable protein II as estimated by its mobility on SDS-PAGE (data not shown). The lipooligosaccharides of strain 340 and Fud 14 were compared following SDS-PAGE and silver staining. No differences in the banding pattern were observed (data not shown).

\section{Growth of N. gonorrhoeae 340 and Fud14 in subcutaneous chambers}

$N$. gonorrhoeae strains 340 and Fudl4 were inoculated into subcutaneous chambers implanted in female ICR mice in order to determine whether the defect(s) in iron utilization in strain Fud14 affected its virulence. The parental strain 340 was highly infectious for subcutaneous chambers with an $\mathrm{ID}_{50}$ of $4.3 \times 10^{1}$ c.f.u.; the $\mathrm{ID}_{50}$ for strain Fud 14 was approximately $1 \times 10^{8}$ c.f.u. (data not shown). Strain 340 was recovered from chamber fluid at $2,5,15$ and $30 \mathrm{~d}$ post-inoculation. The difference in the $\mathrm{ID}_{50}$ values could be the result of differences in serum resistance. However, there were no differences in the degree of killing of strain 340 or strain Fud 14 during a 60 min incubation in fresh $10 \%$ normal mouse serum (data not shown).

When $N$.gonorrhoeae strain Fud 14 was inoculated into chambers $\left(10^{8}\right.$ c.f.u. $)$, viable cells were recovered in $50 \%$ of the mice at $24 \mathrm{~h}$ post-inoculation; only $25 \%$ of the chambers contained viable gonococci by $48 \mathrm{~h}$ and no viable gonococci were recovered after $72 \mathrm{~h}$ (Table 4). In contrast, addition of either haemin or normal human serum to the chamber at the time of inoculation resulted in the recovery of viable gonococci at $72 \mathrm{~h}$ postinoculation in 25 and $50 \%$ of the chambers, respectively. Viable gonococci were present in $25 \%$ of the chambers inoculated with Fudl4 and normal human serum at $240 \mathrm{~h}$ post-inoculation. Estimation of numbers of viable gonococci in chambers suggested that there were fewer viable cells in chambers inoculated with Fud14 than in those with strain 340 (data not shown).

The haem and haemoglobin contents of uninoculated, unsupplemented chamber fluid were $29.95 \mu \mathrm{M}$ and $29.0 \mu \mathrm{M}$, respectively.

\section{Genetics of the iron defect in Fud14}

Attempts to isolate $\mathrm{TF}^{+}$revertants of Fud14 in order to determine whether restoration of the ability to use TF coincided with the ability to grow in mouse subcutaneous chambers were unsuccessful. Since we could not obtain piliated colony types of strain Fud 14 we were unable to transform this strain with chromosomal DNA by standard techniques. Therefore, electroporation was utilized to introduce chromosomal DNA from $N$. gonorrhoeae strain 340 into strain Fud14 with recombinant selection on CDM plates containing $10 \mu \mathrm{M}-\mathrm{TF}(30 \%$ iron-saturated). $\mathrm{TF}^{+}$transformants appeared at a frequency of $4.3 \times 10^{-7}$. Electroporation of strain Fud14 without the addition of chromosomal DNA from strain 340 did not yield any $\mathrm{TF}^{+}$colonies. We chose one $\mathrm{TF}^{+}$ transformant (designated Fud15) for characterization. Strain Fud 15 grew in CDM supplemented with $5 \mu \mathrm{M}$-TF $(30 \%$ iron-saturated) (Fig. 1), but not as rapidly as strain 340. Cultures of strain Fud 15 required an additional $3 \mathrm{~h}$ to reach the same final optical density as that reached by cultures of strain 340 .

$N$. gonorrhoeae strain Fud15 grew in medium supplemented with either heat-inactivated normal human serum $(10 \%)$, ferric citrate or haemoglobin (Table 1 ). 
The amount of ${ }^{55} \mathrm{Fe}$ internalized from $\left[{ }^{55} \mathrm{Fe}\right]$ ferric citrate or $\left[{ }^{55} \mathrm{Fe}\right] \mathrm{TF}$ by Fud 15 was similar to that internalized by strain 340 (data not shown). The outer-membrane protein profile of cells of strain Fud 15 revealed that this transformant produced the $93 \mathrm{kDa}$ protein and low levels of the $57 \mathrm{kDa}$ protein which were not produced by strain Fud14. However, strain Fud15 did not produce the $100 \mathrm{kDa}$ protein which was produced by strain $340 . N$. gonorrhoeae strain Fud 15 ( $10^{7}$ c.f.u.) was also inoculated into mouse subcutaneous chambers and found to be highly infectious with viable organisms recovered at 1,5 and $14 \mathrm{~d}$ post-inoculation.

\section{Discussion}

Despite the relative abundance of iron in the host, there is little free iron due to its sequestration by the ironbinding proteins TF and LF (Griffiths, 1985). Consequently, gonococci and meningococci must possess mechanisms for utilizing the iron associated with TF and LF as well as other potential in vivo iron sources such as haem and haemoglobin.

In humans, TF and LF may be the principal iron sources used by $N$. gonorrhoeae. TF is most likely the iron source used by gonococci causing invasive disease, whereas LF is found on mucosal surfaces and could be used during the establishment of a local infection. Gonococci and meningococci bind only human TF and LF; TF from other sources does not bind nor compete with human TF (Schryvers \& Morris, 1988a,b; Lee \& Schryvers, 1988). These observations have led to speculation that the host specificity of these pathogens may be related to their ability to acquire iron from TF.

$N$. meningitidis (Simonson et al., 1982) and $N$. gonorrhoeae (McKenna et al., 1988) acquire the TFbound iron by an iron-repressible energy-dependent mechanism that requires a functional respiratory chain. The acquisition of TF- or LF-bound iron requires direct contact of the protein with a receptor on the gonococcal cell surface (McKenna et al., 1988). The mechanism by which gonococci release the iron from TF and LF is unclear. However, it is likely that meningococcal and gonococcal iron-regulated proteins play a role in the binding and release of iron from TF and LF, and its transport across the outer and cytoplasmic membranes.

Little is known concerning the mechanisms employed by pathogenic Neisseria to obtain haem-bound iron. It has been suggested that the ability to obtain haem-bound iron by the pathogenic Neisseria may be related to the exposure of the porphyrin ring (Dyer et al., 1987b). Free haemoglobin or haemoglobin bound to haptoglobin can be used as an iron source by most gonococcal and meningococcal strains (West \& Sparling, 1985). $N$. gonorrhoeae and $N$. meningitidis can also utilize free haem as an iron source (Mickelsen \& Sparling, 1981; Yancey \& Finkelstein, 1981), but not when it is complexed to haemopexin or albumin (Dyer et al., 1987b).

In the present study, $N$. gonorrhoeae strain Fud 14 was initially selected because it was unable to utilize Fe-TF efficiently as a source of iron for growth in a plate assay. Strain Fud14 internalized TF-bound iron at a level that was only $25 \%$ of that observed with the parent strain. In spite of this difference, strain Fud14 appeared to bind TF to the same degree as the parent strain. The assay that was used measured specific as well as non-specific binding and gave only rough qualitative results. Therefore, it may not be possible to measure accurately differences in the degree of TF binding by this method. Nevertheless, cells from iron-limited cultures of strains 340 and Fud 14 appeared to bind TF to the same extent.

The defect in the efficiency of the utilization of TFbound iron by strain Fud14 may thus occur after binding of $\mathrm{TF}$ to its receptor. The observation that the ${ }^{55} \mathrm{Fe}$ from $\left[{ }^{55} \mathrm{Fe}\right] \mathrm{TF}$ was bound to the $\mathrm{Fbp}$ isolated from strain Fud 14 suggested that this strain was capable of removing the iron from TF. Previous studies (Mietzner et al., 1987) have determined that when fully expressed, the Fbp comprised between 1 and $3 \%$ of the total cellular protein. SDS-PAGE and Western blot analyses suggested that strains 340 and Fud 14 appeared to produce similar levels of $\mathrm{Fbp}$ when grown under iron-limited conditions. Fbp is a periplasmic protein (Berish et al., 1990) and binds iron transiently suggesting that it has a role in iron uptake (Chen, 1988). Assuming that, on average, Fbp comprised $2 \%$ of the total cellular protein, virtually all of the cellassociated ${ }^{55} \mathrm{Fe}$ in strain Fud14 was bound to the $\mathrm{Fbp}$ (Table 3 ). In contrast, only $28 \%$ of the cell-associated ${ }^{55} \mathrm{Fe}$ was bound to the Fbp isolated from strain 340, indicating that the majority of this iron was associated with other cellular components. Thus, strain Fud14 may not be capable of removing the Fe from Fbp.

Previous studies have suggested that the availability of iron is important in gonococcal and meningococcal pathogenesis (Holbein, 1980; Holbein, 1981; Payne \& Finkelstein, 1975). Corbeil et al. (1979) reported that the addition of $15 \%$ gastric mucin and haemoglobin to the inoculum increased the infectivity of gonococci for the mouse subcutaneous chamber model by more than 100fold. Recently, Keevil et al. (1989) observed that ironlimited gonococci were highly virulent in the guinea pig subcutaneous chamber model.

The results presented in this study begin to define a role for iron utilization in the in vivo growth of $N$. gonorrhoeae. The inability of $N$. gonorrhoeae strain Fud 14 to utilize transferrin-bound iron or haemoglobin in vitro was correlated with the inability of this mutant to grow in mouse subcutaneous chambers. The ID ${ }_{50}$ of strain Fud 14 
was greater by a factor of $10^{7}$ than that needed for the infection of chambers by the parental strain. The specific iron source utilized by $N$. gonorrhoeae in this model is unknown, although our results suggest that it could be haemoglobin. In the absence of infection, stainless steel chambers usually become encapsulated with dense connective tissue, which can alter the rate and type of serum components that gain access to the chamber fluid (Arko, 1989). The percentage of transferrin found in guinea pig chamber fluid is approximately $90 \%$ of that found in fresh normal guinea pig serum (Arko \& Balows, 1986). If this holds true for the mouse model, it would indicate that mouse transferrin is available to $N$. gonorrhoeae growing in these chambers. However, Schryvers \& Morris (1988a) demonstrated (using an in vitro binding assay) that $N$. gonorrhoeae specifically bound human transferrin and did not bind transferrin from other species, i.e. rat, horse, cow or mouse. $N$. gonorrhoeae strains 340 and Fud 14 did not utilize mouse transferrin as a source of iron in vitro. In addition, these strains could not grow in vitro in CDM supplemented with $10 \%$ normal mouse serum. Whether $N$. gonorrhoeae can utilize the iron on mouse transferrin in vivo remains to be determined.

Chandler et al. (1976) observed haemorrhaging into subcutaneous chambers implanted in either guinea pigs or mice. The presence of erythrocytes in the chamber fluid (data not shown) suggested that haemoglobin could be a potential iron source for strain 340 . Analysis of uninoculated chamber fluid indicated that a substantial amount of haem was present in the chamber fluid. However, the majority of the haem in chamber fluid was apparently present as haemoglobin. Gonococci and meningococci can utilize haemoglobin from species other than humans as an in vitro and in vivo source of iron (Dyer et al., 1987b). The inability to utilize haemoglobin as an iron source may thus explain why strain Fud14 did not grow in subcutaneous chambers. These results suggest that the free haem concentration in unsupplemented chamber fluid was insufficient to sustain the growth of strain Fud 14. In humans, the majority of haem is bound tightly to haemopexin or serum albumin from which $N$. gonorrhoeae is unable to obtain the haem for growth.

The iron source utilized by Fud14 in normal human serum may be haem, since dialysis of normal human serum by using molecular mass 1000 exclusion tubing removed the growth stimulating component. Analysis of the dialysate confirmed that haem was removed from normal human serum during the dialysis step.

Supplementation of mouse subcutaneous chambers with haemin, an iron source which Fud 14 could use for in vitro growth, resulted in the growth of this strain in vivo for several days. Presumably, this strain could no longer survive once it exhausted the supply of exogenously added haemin.

The ability of strain Fud14 to utilize haemin as the sole source of iron for in vitro growth suggests that the utilization of haem iron occurred by a different pathway than that of haemoglobin or TF-bound iron. Circumventing the block in TF-bound iron and haemoglobin utilization via the addition of haemin restored the ability of Fud14 to grow in vivo. West \& Sparling (1985) observed that the expression of gonococcal iron-repressible proteins varied depending upon the iron source. These results are compatible with the idea that multiple iron acquisition systems may be operative in the gonococcus.

It was not possible to ascribe the phenotypic properties of strain Fud14 to a single mutation. Introduction of wild-type DNA into this strain by electroporation resulted in a $\mathrm{TF}^{+}$strain that had regained most, but not all of the properties of the parental strain. However, we could not differentiate between a single mutation and closely linked mutations due to the size of the DNA fragments used for electroporation. Additional experiments to resolve this question are currently in progress.

In summary, we have demonstrated that gonococci must have a source of utilizable iron for in vivo growth. Moreover, gonococci appear to possess more than one pathway for the uptake of iron. Future experiments are planned to delineate these pathways.

The authors would like to acknowledge Jackie Curlew and Enid Bulboff for the typing of this manuscript. These studies were supported, in part, by Public Health Service Grant AI 22148 from the National Institutes of Health. C. A.G. was the recipient of a National Research Council Fellowship.

\section{References}

Ala'Aldeen, D. A., Davies, H. A., Wall, R. A. \& Borriello, S. P. (1990). The 70 kilodalton iron regulated protein of Neisseria meningitidis is not the human transferrin receptor. FEMS Microbiology Letters 69, 37-42.

ARChibald, F. S., \& DEVoE, I. W. (1979). Removal of iron from human transferrin by Neisseria meningitidis. FEMS Microbiology Letters 6, 159-162.

ARKo, R. J. (1989). Animal models for pathogenic Neisseria species. Clinical Microbiology Reviews 2, suppl. S56-S59.

ArKo, R. J. \& Balows, A. (1986). Animal models of experimental gonococcal infection. In Experimental Models in Antimicrobial Chemotherapy, vol. 1. pp. 355-369. Edited by O. Zak \& M. A. Sande. New York: Academic Press

Berish, S. B., Chen, C. Y. \& MoRSE, S. A. (1990). Expression of the gonococcal Fbp gene in Escherichia coli. Abstracts from the Annual Meeting of the American Society for Microbiology, Anaheim, California, USA. Abstract D150, p. 105.

Bullen, J. J. (1981). The significance of iron in infection. Reviews of Infectious Disease 3, 1127-1138.

Chandler, F. W., Kraus, S. J. \& Watts, J. C. (1976). Pathological features of experimental gonococcal infection in mice and guinea pigs. Infection and Immunity 13, 909-914. 
CHEN, C. Y. (1988). Membrane proteolipids and iron regulated proteins of Neisseria gonorrhoeae. $\mathrm{PhD}$ thesis, Oregon Health Sciences University, Portland, Oregon, USA.

Cone, R., Hasan, S. K., Loun, J. W. \& Morgan, A. R. (1976). The mechanism of the degradation of DNA by streptonigrin. Canadian Journal of Biochemistry 54, 219-223.

Corbeil, L. B., Wunderlich, A. C., Corbeil, R. R., McCutchan, J. A., ITo, J. I., JR \& BRAUDE, A. I. (1979). Disseminated gonococcal infection in mice. Infection and Immunity 26, 984-990.

Dyer, D. W., McKenna, W., Woods, J. P. \& Sparling, P. F. $(1987 a)$.Isolation by streptonigrin enrichment and characterization of a transferrin-specific iron uptake mutant of Neisseria meningitidis. Microbial Pathogenesis 3, 351-363.

Dyer, D. W., West, E. P. \& SParling, P. F. (1987b). Effects of serum carrier proteins on the growth of pathogenic Neisseria with haembound iron. Infection and Immunity 55, 2171-2175.

Dyer, D. W., West, E. P., McKenna, W., Thompson, S. A. \& SPARLING, P. F. (1988). A pleiotropic iron-uptake mutant of Neisseria meningitidis lacks a 70-kilodalton iron regulated protein. Infection and Immunity 56, 977-983.

FaLK, J. E. (1964). Porphyrins and Metalloporphyrins, vol. 2, pp. 181182. Amsterdam: Elsevier.

Griffiths, E., Stevenson, P. \& Ray, A. (1990). Antigenic and molecular heterogeneity of the transferrin-binding protein of Neisseria meningitidis. FEMS Microbiology Letters 69, 31-36.

GRIFFITHS, E. \& HUMPHREYS, J. (1980). Isolation of enterochelin from peritoneal washings of guinea pigs lethally infected with Escherichia coli. Infection and Immunity 28, 286-289.

Griffiths, E., Stevenson, P. \& Joyce, P. (1983). Pathogenic Escherichia coli express new outer membrane proteins when growing in vivo. FEMS Microbiology Letters 16, 95-99.

GRIFFITHS, E. (1985). Candidate virulence markers. In Virulence of Escherichia coli, pp. 193-226. Edited by M. Sussman. London: Academic Press.

Holbein, B. E. (1980). Iron-controlled infection with Neisseria meningitidis in mice. Infection and Immunity 29, 886-891.

HoLBEIN, B. E. (1981). Enhancement of Neisseria meningitidis infection in mice by addition of iron bound to transferrin. Infection and Immunity 34, 120-125.

Keevil, C. W., Davies, D. B., Spillane, B. J. \& Mahenthiralingam, E. (1989). Influence of iron-limited and replete continuous culture on the physiology and virulence of Neisseria gonorrhoeae. Journal of General Microbiology 135, 851-863.

LAEMMLI, U. K. (1970). Cleavage of structural proteins during the assembly of the head of bacteriophage T4. Nature, London 227, 680 685

LEE, B. C. \& SCHRYvers, A. B. (1988). Specificity of the lactoferrin and transferrin receptors in Neisseria gonorrhoeae. Molecular Microbiology 2, 827-829.

McKenna, W. R., Mickelsen, P. A., Sparling, P. F. \& Dyer, D. W. (1988). Iron uptake from lactoferrin and transferrin by Neisseria gonorrhoeae. Infection and Immunity 56, 785-791.

MARMUR, J. (1961). A procedure for the isolation of deoxyribonucleic acid from microorganisms. Journal of Molecular Biology 3, 208-218.

Mickelsen, P. A. \& Sparling, P. F. (1981). Ability of Neisseria gonorrhoeae, Neisseria meningitidis and commensal Neisseria species to obtain iron from transferrin and iron compounds. Infection and Immunity 33, 555-564.

Mickelsen, P. A., Blackman, E. \& Sparling, P. F. (1982). Ability of Neisseria gonorrhoeae, Neisseria meningitidis and Neisseria species to obtain iron from lactoferrin. Infection and Immunity 35, 915-920.
Mietzner, T. A., Luginbuhl, G. H., Sandstrom, E. \& Morse, S. A. (1984). Identification of an iron-regulated 37,000-dalton protein in the cell envelope of Neisseria gonorrhoeae. Infection and Immunity 45, $410-416$.

Mietzner, T. A., Barnes, R. C., Jeanlouis, Y. A., Shafer, W. M. \& MORSE, S. A. (1986). Distribution of an antigenically related ironregulated protein among the Neisseria spp. Infection and Immunity 51, $60-68$.

Mietzner, T. A., Bolan, G., Schoolnik, G. K. \& Morse, S. A. (1987). Purification and characterization of the major iron-regulated protein expressed by pathogenic Neisseria. Journal of Experimental Medicine 165, 1041-1057.

Morse, S. A. \& BARTENSTEIN, L. (1980). Purine metabolism in Neisseria gonorrhoeae the requirement for hypoxanthine. Canadian Journal of Microbiology 26, 13-20.

NeILANDS, J. B. (1981). Microbial iron compounds. Annual Review of Biochemistry 50, 715-731.

Payne, S. M. \& Finkelstein, R. A. (1975). Pathogenesis and immunology of experimental gonococcal infection: role of iron in virulence. Infection and Immunity 12, 1313-1318.

SCHRYVERS, A. B. (1988). Characterization of the human transferrin and lactoferrin receptors in Haemophilus influenzae. Molecular Microbiology 2, 467-472.

SCHRYVERS, A. B. \& MORRIS, L. J. (1988a). Identification and characterization of the transferrin receptor from Neisseria meningitidis. Molecular Microbiology 2, 281-288.

SCHRYVERS, A. B. \& MORRIS, L. J. (1988b). Identification and characterization of the human lactoferrin-binding protein of Neisseria meningitidis. Infection and Immunity 56, 1144-1149.

SCHRYVERS, A. B. \& LEE, B. C. (1989). Comparative analysis of the transferrin and lactoferrin-binding proteins in the family Neisseriaceae. Canadian Journal of Microbiology 35, 409-415.

Sciortino, C. V. \& Finkelstein, R. A. (1983). Vibrio cholerae expresses iron-regulated outer membrane proteins in vivo. Infection and Immunity 42, 990-996.

Simonson, C., BRENER, D. \& DeVoe, I. W. (1982). Expression of a high affinity mechanism for acquisition of transferrin iron by Neisseria meningitidis. Infection and Immunity 36, 107-113.

TSaI, J., DYeR, D. W. \& SParling, P. F. (1988). Loss of transferrin receptor activity in Neisseria meningitidis correlates with inability to use transferrin as an iron source. Infection and Immunity 56, 31323138

West, S. E. H. \& Sparling, P. F. (1987). Aerobactin utilization by Neisseria gonorrhoeae and cloning of a genomic DNA fragment that complements Escherichia coli fhuB mutations. Journal of Bacteriology 169, 3414-3421

West, S. E. H., Mickelsen, P. A., Dyer, D. W. \& Sparling, P. F. (1985). Iron acquisition by the pathogenic Neisseria. In The Pathogenic Neisseria, pp. 415-422. Edited by G. A. Schoolnik, G. F. Brooks, S. Falkow, C. E. Frasch, J. S. Knapp, J. A. McCutchan \& S. A. Morse. Washington, DC: American Society for Microbiology.

Wong, K. H., Arko, R. J., Schalla, W. O. \& Steurer, F. J. (1979). Immunological and serological diversity of Neisseria gonorrhoeae: Identification of new immunotypes and highly protective strains. Infection and Immunity 23, 717-722.

YANCEY, R. J. \& Finkelstein, R. A. (1981). Assimilation of iron by pathogenic Neisseria spp. Infection and Immunity 32, 592-599

YeOWELL, H. N. \& WhITE, J. R. (1982). Iron requirement in the bactericidal mechanism of streptonigrin. Antimicrobial Agents and Chemotherapy 22, 961-968. 